\title{
Assessing Water Quality Index in River Basin : Fuzzy Inference System Approach
}

\section{Herman Umbau Lindang, 2 Zamali Hj Tarmudi, 3 Ajimi Jawan}

1School of Biological Sciences, Faculty of Applied Sciences, Universiti Teknologi MARA Shah Alam, 40450 Selangor. 2 Department of Mathematics, Faculty of Computer and Mathematical Sciences, Universiti Teknologi MARA Sabah, Locked Bag 71, 88997 Kota Kinabalu, Sabah. 3 Department of Biological Sciences, Faculty of Applied Sciences, Universiti Teknologi MARA Sabah, Locked Bag 71, 88997 Kota Kinabalu, Sabah 1 Corresponding Author : email: hermanumbau@gmail.com Tel.: 60013-8362140, Fax: 6088-325164

This is an open access article distributed under the Creative Commons Attribution License, which permits unrestricted use, distribution, and reproduction in any medium, provided the original work is properly cited.

\section{ARTICLE DETAILS}

Article history:

Received 22 January 2017 Accepted 03 February 2017

Available online 05 February 2017

Keywords:

Fuzzy Inference System (FIS), Water Quality Assessment, River Basin

\section{ABSTRACT}

Water Quality Index is an important water assessment that sustain and conserve the aquatic ecosystem. In Malaysia, the current classiðication practice on Department of Environmental Water Quality Index (DOE WQI) shows rigid value in term of assessing the input of parameters that close to a class boundary. Hence, this study proposed a technique to assess the parameters in a holistic manner by using the Fuzzy Inference System (FIS). The approach as an assessment tool represents the classes of various ranges and aggregating the parameters using membership function and Centroid Function respectively. A numerical example based on actual data from one of the sampling station from Inanam Likas River Basin was adapted in this study. It was adapted to demonstrate the proposed approach. Findings shown using the proposed methods indicate that the river has Poor water status. Overall, FIS is able to assess the parameters and execute into a single index that represent the condition from poor to excellent scales of the water quality

\section{0}

\section{INTRODUCTION}

The effect of earthquakes on the river basin affects the quality of the river The changes of selected parameters will impose problems towards the living environment. The severity depending on the changes on the parameters has different effects towards the life cycle of the aquatic ecosystem. For example low dissolved oxygen value affect the diversity of the aquatic organism and changes in $\mathrm{pH}$ will affect the heavy metal solubility in the river that can cause release of toxic metal ions. Natural phenomenon such as the earthquake amplifies the anthropogenic effects towards the ecosystem. Moreover, research studies have also revealed that human activities from the industrial activity have harmful effect towards the ecosystem. These factors shows strong relationship with the usage of land and this include the river basin (Liu \& Zou, 2012). With the external factors that act upon the river, it is important for every river to be monitor and assessed in respect to the physicochemical and biological factor.

Department of Environment (DoE) in Malaysia uses DoE Water Quality Index (DoE WQI) and National Water Quality Standards (NWQS) to assess the quality status of the river. WQI have 5 classes in the form of range and the level of water pollution is labeled using classification Class 1, Class 2(A) and (B), Class 3 Class 4 and Class 5 (DoE, 2014). WQI is an assessment of water that involves local necessity pollution status on the river basin. Table 1 represents selected parameters that have been classified according to its current classification used by the DoE in Malaysia. Table 2 summarizes the classification of water quality on selected parameters according to DoE WQI and NWQS for Malaysia.

The beauty of formulating and constructing environmental assessment model with a comprehensive assessment and reliable computational framework of data plays a significant part. Past environmental studies has proved that there are different conditions of ecosystem, variability of subjectivity and uncertainties in the managing the environment as shown by Chen, Rui, Li, \& Zhang (2014), Franz et al. (2013) ,Ocampo-Duque et al. (2013) and Gharibi et al. (2012) Complimentary to fact, assessing the surface water quality involve with human subjectivity because the water evaluation can exist in different types of data such as linguistic, interval and crisp data. The existence of different forms of information for the assessment of surface water tends to be complex when it comes to analyze the numerous water variables at simultaneously. Therefore, the complexity of assessing the water can be managed well by using fuzzy sets theory approach. One of the Fuzzy's application approaches is Fuzzy Inference System (FIS). It uses the If-Then rules that make the model easier to reflect the subjective and complex nature of assessing and managing the river basin. Study done by Carbajal-Hernández et al. (2012) and Mahapatra et al. (2011) has shown that FIS is very effective in executing a single outcome of water index from multiple number of water variables.

Therefore, in this paper we propose a water assessment evaluation using FIS by adapting the current classification of water status from the DoE WQI. To do so, this paper is structured as follows: Section 2 briefly identify and discuss the problems that are being highlighted in this study; Section 3 and 4 both discuss the background theory and implementation of proposed methods for illustration purposes, respectively; and finally, Section 5 concludes the overall findings of the paper.

\section{Table 1 : Classification levels for related parameters}

\begin{tabular}{|c|c|c|c|c|c|}
\hline \multirow{2}{*}{ PARAMETER } & \multicolumn{5}{|c|}{ CLASSES } \\
\hline & I & II & III & IV & $\mathrm{v}$ \\
\hline DO $(\mathrm{mg} / \mathrm{l})^{* *}$ & $>7$ & {$[5,7]$} & {$[3,5]$} & $<3$ & $<1$ \\
\hline $\mathrm{NH}_{3} \mathrm{~N}(\mathrm{mg} / \mathrm{l})^{* *}$ & $<0.1$ & {$[0.1,0.3]$} & {$[0.3,0.9]$} & {$[0.9,2.7]$} & $>2.7$ \\
\hline Turbidity (NTU) ** & 5 & 50 & - & - & - \\
\hline $\mathrm{pH}^{* *}$ & {$[6.5,8.5]^{*}$} & {$[6,7]$} & {$[5,6]$} & $<5$ & $>5$ \\
\hline
\end{tabular}


Table Z: Water classes and Uses

\begin{tabular}{|l|l|}
\hline \multicolumn{1}{|c|}{ CLASS } & \\
\hline \multirow{4}{*}{ Class I } & Conservation of natural environment. \\
\cline { 2 - 2 } & Water Supply- Practically no treatment necessary. \\
\cline { 2 - 2 } & Fishery -Very sensitive aquatic species. \\
\hline \multirow{2}{*}{ Class II } & Conventional treatment required \\
\cline { 2 - 2 } & Fishery - Sensitive aquatic species \\
\cline { 2 - 2 } & Recreational use with body contact \\
\hline \multirow{2}{*}{ Class III } & Water supply - Extensive treatment required. \\
\cline { 2 - 2 } & Fishery - Common, of economic value and tolerant species; livestock drinking. \\
\hline Class IV & Irrigation \\
\hline Class V & None of the above \\
\hline
\end{tabular}

2.0

\section{PROBLEM IDENTIFICATION}

Nowadays, different water quality assessment proposed by international researchers shows that each assessment have their own emphasize based on the water bodies main function. The current range implemented by Department of Environment through DOE-WQI for classi囚ication of parameters indexes showed less \lexibility in judging the concentration of a parameter that is close to the boundary. Inputs of hydrological data into interval sets of data had shown the uncertainties of inputs in evaluating the data. Uncertainties of inputs can be evaluate effectively by using fuzzy logic in water assessment. Therefore, this paper proposes to assess the water parameter by applying into FIS to execute the water assessment

\subsection{THE BASIC CONCEPT AND PROPOSED METHOD}

\subsection{Fuzzy Inference Systems}

Hydrology data exist in a crisp data and being classi囚ied into certain range respective to its parameter. The existence of interval data in classifying the water quality shows the existence of subjectivity in the classi囚ication process. Similarly Fuzzy Inference System (FIS) has been an effective and holistic tool to evaluate and execute any forms of subjective data into a single output.

In this paper, the current water quality classi囚ication will be adapted into FIS for the execution of water status. The constructed outcome from the propose analysis was Excellent, Very Good, Good, Moderately Poor and Poor. Counter back strategy implemented in this paper to solve the evaluation of data on the boundary of a range was resolve as well by using FIS. That is to say, FIS is a process of formulating a mapping from a given multiple input to a single output using fuzzy logic. The process of fuzzy inference involves three important concepts: membership function, logical operations and If - Then rules (Carbajal-Hernández, Sánchez-Fernández, Carrasco-Ochoa, \& Martínez-Trinidad, 2012; Ocampo-Duque, Osorio, Piamba, Schuhmacher, \& Domingo, 2013)

\subsection{Proposed Methods of FIS into Water Quality Assessment}

Step 1: Fuzzy Inputs

This paper proposes the uses the inputs of hydrology data into the membership functions as the 囚irststeps. It was implemented in the inputs of the FIS as membership functions. Every classiðication of the parameters with regards to its possible class were represented using membership functions. A membership functions $(\mu)$ transforms the real value obtained into a $[0,1]$ value. Trapezoidal membership functions (TrapMFs) de区inethe input transformation of the FIS and were represented as in expression (1).

$\mu(x, a, b, c, d)=\min \{(x-a) /(b-a), 1,(d-x) /(d-c)\}$

where $\mathrm{x}$ is a water quality variable; $\mathrm{a}, \mathrm{b}, \mathrm{c}$ and $\mathrm{d}$ are membership parameters Table 3 shows the value of each membership parameters to be adapted into expression (1).

\begin{tabular}{|c|c|c|c|c|c|}
\hline PARAMETERS & CLASSIFICATION & $a$ & $\boldsymbol{b}$ & $c$ & $d$ \\
\hline \multirow[t]{5}{*}{ DO (mg/l) } & Class 1 & 7 & 7 & 50 & 50 \\
\hline & Class 2 & 5 & 5 & 7 & 7 \\
\hline & Class 3 & 3 & 3 & 5 & 5 \\
\hline & Class 4 & 1 & 1 & 3 & 3 \\
\hline & Class 5 & 0 & 0 & 1 & 1 \\
\hline \multirow[t]{5}{*}{$\mathrm{NH}_{3} \mathrm{~N}(\mathrm{mg} / \mathrm{l})$} & Class 1 & 0 & 0 & 0.1 & 0.1 \\
\hline & Class 2 & 0.1 & 0.1 & 0.3 & 0.3 \\
\hline & Class 3 & 0.3 & 0.3 & 0.9 & 0.9 \\
\hline & Class 4 & 0.9 & 0.9 & 2.7 & 2.7 \\
\hline & Class 5 & 2.7 & 2.7 & 50 & 50 \\
\hline \multirow[t]{5}{*}{ Turbidity (NTU) } & Class 1 & 0 & 5 & 50 & 50 \\
\hline & Class 2 & 50 & 50 & 150 & 150 \\
\hline & Class 3 & na & na & $n a$ & $n a$ \\
\hline & Class 4 & na & na & $n a$ & na \\
\hline & Class 5 & na & na & $n a$ & $n a$ \\
\hline \multirow[t]{5}{*}{$\mathrm{pH}$} & Class 1 & 6.5 & 6.5 & 8.5 & 8.5 \\
\hline & Class 2 & 6 & 6 & 7 & 7 \\
\hline & Class 3 & 5 & 5 & 6 & 6 \\
\hline & Class 4 & 0 & 0 & 5 & 5 \\
\hline & Class 5 & 5 & 5 & 14 & 14 \\
\hline
\end{tabular}



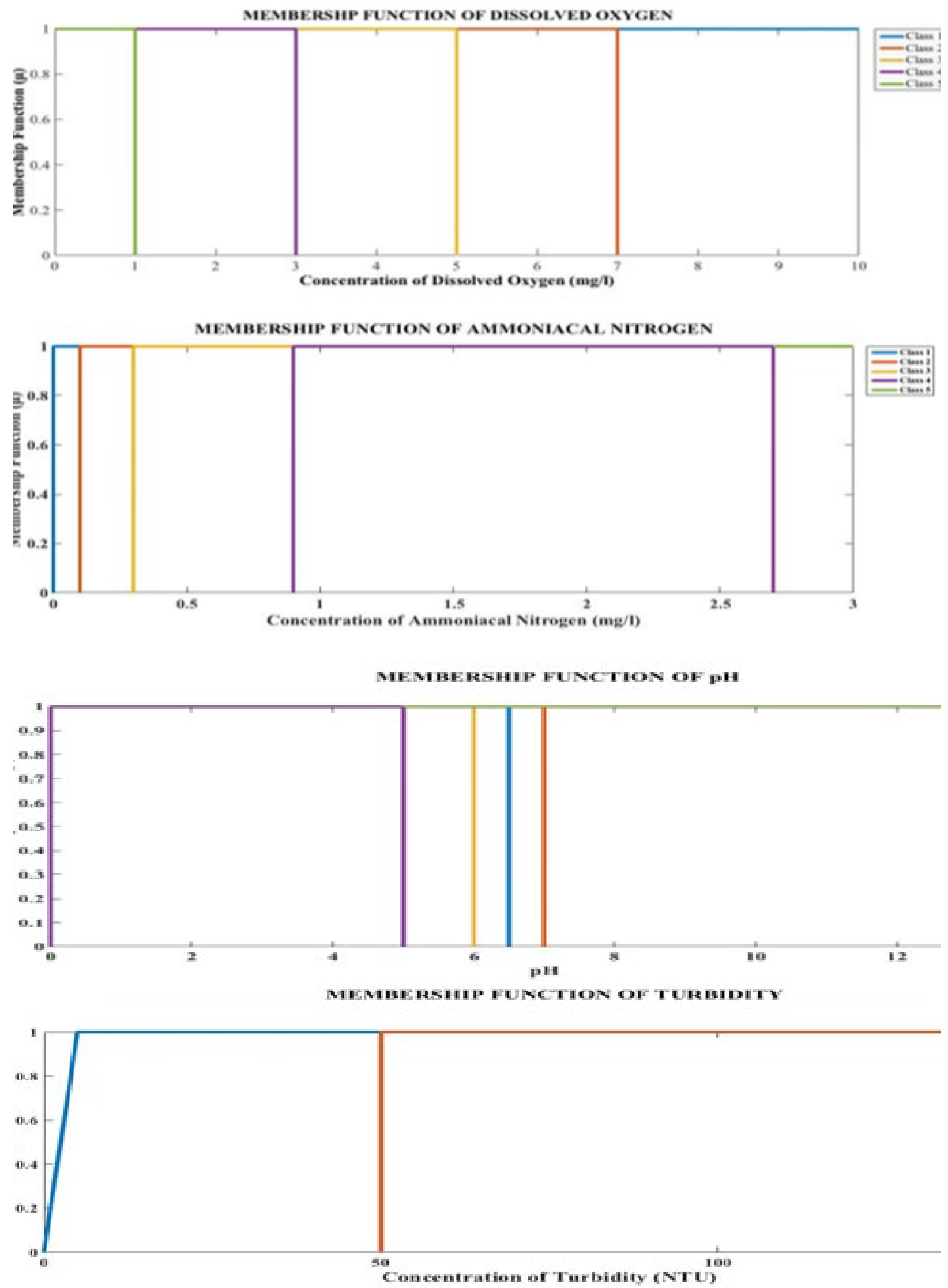

re 1: Membership functions for water parameters: dissolved oxygen, Ammoniacal Nitrogen, $\mathrm{pH}$ a 


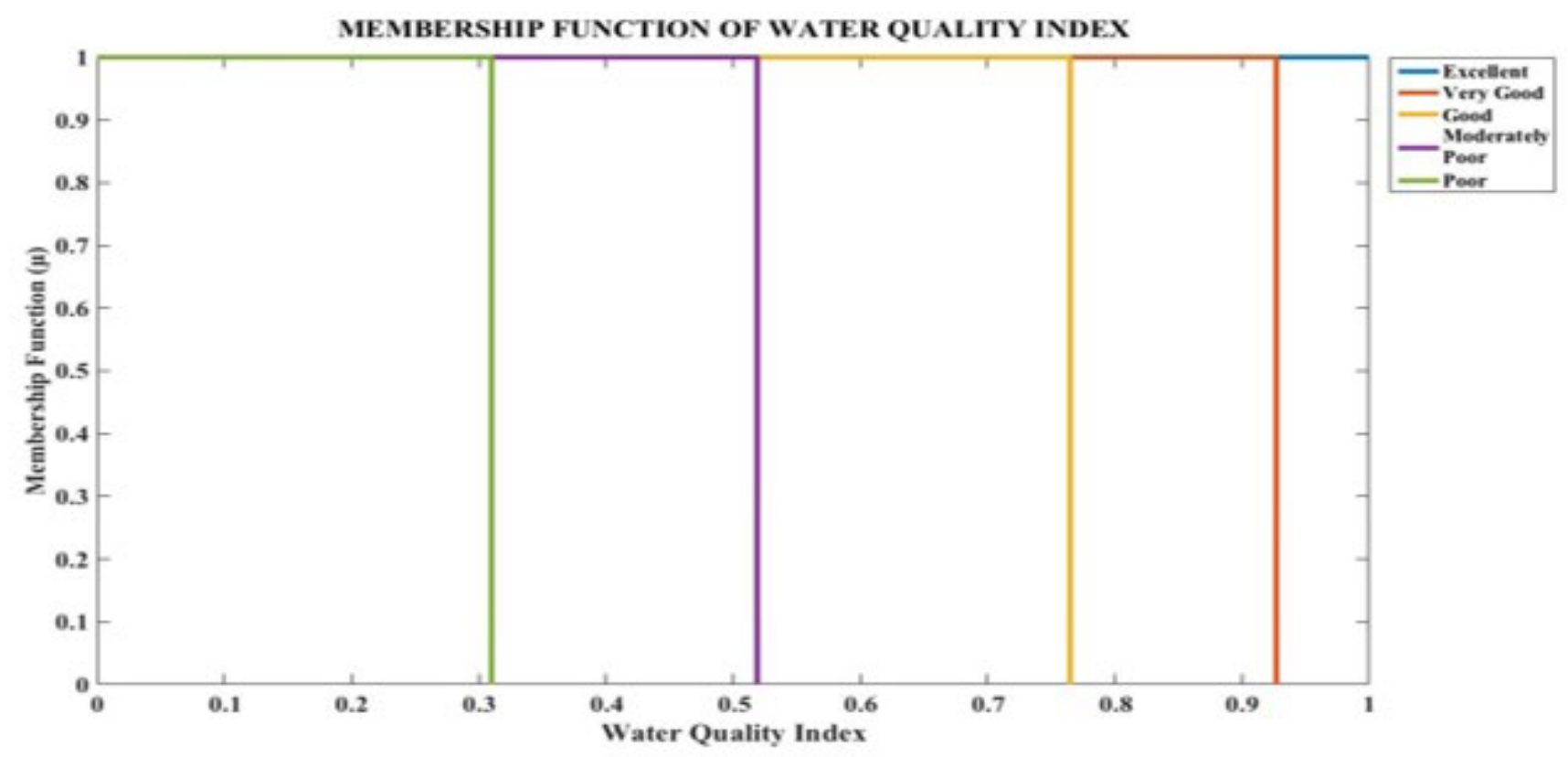

Figure 2: Membership functions for Water Quality Index Figure 2: Membership functions for Water Quality Index

Figure 1 shows the representation of classification of dissolved oxygen (DO), ammoniacal nitrogen (NH3N), $\mathrm{pH}$ and turbidity in TrapMFs. Figure 2 shows the representation of Water Quality Index in TrapMFs. The constructed TrapMFs was adapted from the DoE WQI that was still used in Malaysia.

\section{Step 2: Fuzzy Operators}

The membership degree of each part of rule antecedent is computed after the inputs are fuzzified. Three fuzzy operators as had shown in expression (2), (3) and (4) were used. The operators are union (OR), intersection (AND) and negation (NOT).

Union (OR)

$(\mathrm{x})\}$

Intersection (AND)

Negation (NOT)

Step 3: Inference Rules (Reasoning Process)

Subjectivity may refer to the specific interpretations of any aspect of experiences. Likewise in this paper, it refers to the possibilities of the crisp data input in the classification of data in the forms of interval set used in evaluating the water. As reported in the annual report of Department of Environment (2014), water experts' uses linguistic expression such as Class 1 , Class 2, Class 3, Class 4 and Class 5 to represent the status of the water. The sets of classification constructed used in this paper were described. Dissolved Oxygen $=\mathrm{DO}=$ Class 1, Class2, Class 3 , Class 4, Class 5$\} \quad=\quad\{\mathrm{C} 1, \mathrm{C} 2, \mathrm{C} 3, \mathrm{C} 4, \mathrm{C} 5\}$

Ammoniacal Nitrogen $=$ NH3N $=\{$ Class 1, Class2, Class3, Class 4, Class 5$\}=\quad\{\mathrm{C} 1, \mathrm{C} 2, \mathrm{C} 3, \mathrm{C} 4, \mathrm{C} 5\}$

$\mathrm{pH}=\mathrm{pH}=\{$ Class 1, Class2, Class3, Class 4 , Class 5$\}=\{\mathrm{C} 1, \mathrm{C} 2, \mathrm{C} 3, \mathrm{C} 4, \mathrm{C} 5\}$

Turbidity $\quad$ Turb $=\{$ Class 1, Class 2$\}=$ $\{\mathrm{C} 1, \mathrm{C} 2\}$

The terms representing each set have the following meaning: $\mathrm{C} 1$ as Class 1 , C2 as Class 2, C3 as Class 3, C4 as Class 4 and C5 as Class 5.

As an illustration of application on River A, if the dissolved oxygen (DO) in the water is Class 1 , the ammoniacal nitrogen (NH3N) level is Class 1 , the $\mathrm{pH}$ is Class 1 and the level of turbidity is Class 1 , then the expected water quality is excellent. These linguistic forms of information can be interpreted into fuzzy language. The robustness of the systems also depends on the number and quality of the rules constructed for the evaluation using FIS. As demonstrated in this paper, there were 250 rule constructed and it reflects the possible inputs of the total parameter involve in the assessment. To illustrate some of the sets constructed to represent the parameters used in this paper, the first 6 th rules and the 250th rules were described as follows.
Rules 1:

If DO is C1 AND NH3N is C1 AND pH is C1 and Turb is C1 then WQI is Excellent.

Rules 2:

IfDO is C1 AND NH3N is C1 AND pH is C1 and Turb is C2 then WQI is Excellent.

Rules 3:

If DO is C1 AND NH3N is C2 AND pH is C1 and Turb is C1 then WQI is Excellent.

Rules 4:If DO is C1 AND NH3N is C2 AND pH is C1 and Turb is C2 then WQI is Very Good.

Rules 5:

If DO is C1 AND NH3N is C3 AND pH is C1 and Turb is C1 then WQI is Excellent.

Rules 6:

If DO is C1 AND NH3N is C3 AND pH is C1 and Turb is C2 then WQI is Very Good.

Rules 250:

If DO is C5 AND NH3N is C5 AND pH is C5 and Turb is C5 then WQI is Poor. The output fuzzy rule then computed using the fuzzy operator AND,

$$
m_{R}=\min \left\{m_{D o}^{i}, m_{N_{3} N}^{i}, m_{P H}^{k}, m_{T u r b}^{l}\right\}
$$

where $\mathrm{i}, \mathrm{j}, \mathrm{k}$ and $\mathrm{l}$ are the different levels of concentration (Class 1 , Class 2 , Class 3, Class 4, Class 5 respectively) depends on each parameters.

Step 4: Aggregation

The membership function will be aggregated and produce a single output after the being used different set of rules and being matched with fuzzy outputs $\left(\mu_{-} \mathrm{R}\right)$. The combination of the rules is called aggregation. The aggregation used to fuzzy union all output in the FIS is the maximum methods (Carbajal-Hernández et al., 2012).

Step 5: Defuzification

Next, the different water quality condition obtained in a graph will have be obtained. Centroid function (CF) returns the center of area under the curved formed by the output fuzzy function according to expression 6 :

$$
\mathrm{CF}=\frac{\text { Òx } m_{\mathrm{ut}}(\mathrm{x}) \mathrm{dx}}{\mathrm{O} m_{\mathrm{ut}}(\mathrm{x}) \mathrm{dx}}
$$

The output of the center of area by centroid function determines the input value to be classified into the classification of water status from Poor to Excellent accordingly. The different water quality status from poor to excellent can be within this range and normalization of results was done using expression 7 . The output value of the final evaluation was in the range of $[0,1]$. 


$$
\mathrm{WQI}=\frac{\mathrm{CF}-\min (\mathrm{CF})}{\max (\mathrm{CF})-\min (\mathrm{CF})}
$$

4.0 IMPLEMENTATION AND DISCUSION

To demonstrate our proposed method applied, we adapted one of our water quality data taken from Inanam River, Sabah. The data was tabulated in Table 4

\begin{tabular}{|c|c|c|c|c|c|}
\multirow{2}{*}{$\begin{array}{c}\text { Location } \\
\text { of Water } \\
\text { Sampling }\end{array}$} & GPS Location & \multicolumn{4}{|c|}{ Parameters } \\
\cline { 3 - 6 } & & $\mathrm{pH}$ & $\mathrm{DO}(\mathrm{mg} / \mathbf{l})$ & $\mathrm{NH}_{3} \mathrm{~N}(\mathrm{mg} / \mathrm{l})$ & $\begin{array}{c}\text { Turbidity } \\
\text { (NTU) }\end{array}$ \\
\hline $\begin{array}{c}\text { Klombong } \\
\text { Industrial Area }\end{array}$ & $\begin{array}{l}05^{\circ} 59.354^{\prime} \mathrm{N} \\
116^{\circ} 07.250^{\prime} \mathrm{E}\end{array}$ & $\begin{array}{c}8.84 \\
{ }^{*}(8.82-8.87)\end{array}$ & $\begin{array}{c}1.347 \\
{ }^{*}(1.26-1.42)\end{array}$ & $\begin{array}{c}{ }^{*}(0.56-0.83) \\
0.673\end{array}$ & ${ }^{*}(593-717)$
\end{tabular}

* Average range of each parameters

Given a situation that obeys the rule constructed in Rule 196, 197, 198 and Rule 199, having their parameters DO, NH3N, pH and Turbidty and their values of $1.347 \mathrm{mgl}-1,0.673 \mathrm{mgl}-1,8.84 \mathrm{mgl}-1$ and 643.667 NTU respectively.
Using the propose methods stated in expression (1) untill (7), the water quality index can be evaluate using the FIS. The execution of assessment was computed using Matlab 2015b as had shown in Figure 3

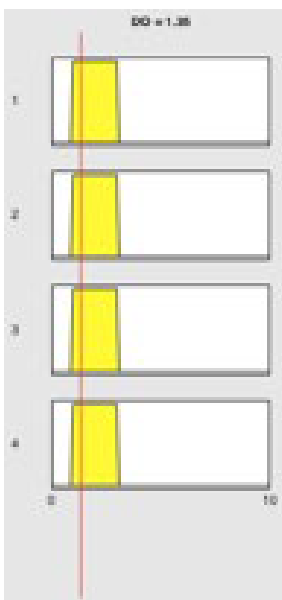

Figure 3: Fuzzy inference diagram for the water quality problem with four parameters and 4 rules. Rules 196,197, 198 and 199 were used to exemplify the defuzziðication process.

Based on the calculation computed using the data taken, the river in Inanam Likas River at the speci囚ied location was 0.155 and classiðied as Poor. It indicates the river is at it worst water quality. As re冈lected in Table 2, Class 5 of water status was not suitable as habitat for the aquatic ecosystem and utilize by humans. Poor condition of the river shows that the river is unhealthy.It affects the food web and the natural function of the river (Aweng, Imis, \& Maketab, 2011).

Even though the numerical example only implies only on fourselected parameters, the expected results can be derived using other parameters as long as the representing the range of parameters involves is adapted into the TrapMFs.

5.0 CONCLUSION

In this paper, we have applied the Fuzzy Inference System (FIS) to evaluate the water assessment by using our own hydrological data obtained from the Klombong Industrial area. It is clearly seen that the proposed method are capable to evaluate the status of the water and the process are less complex and straightforward. Furthermore, this reduces the time required to analyze the hydrological data to determine the status of the water. In short, FIS have shown to be one of the effective and less complex tools to assess the quality of water in a river basin. In the future, the proposed method can be validated using Sensitivity Analysis

\section{Acknowledgements}

The author would like to acknowledge Ministry of Higher Education for providing the fund through 600-RMI/RACE 16/6/2 (17/2013). The author is also very grateful to his supervisor and co-supervisor for their fruitful review and constructive comments to improve the content of this paper.

\section{References}

Carbajal-Hernández, J. J., Sánchez-Fernández, L. P., Carrasco-Ochoa, J. a., \& Martínez-Trinidad, J. F. (2012). Immediate water quality assessment in shrimp culture using fuzzy inference systems. Expert Systems with Applications, 39(12), 10571-10582.
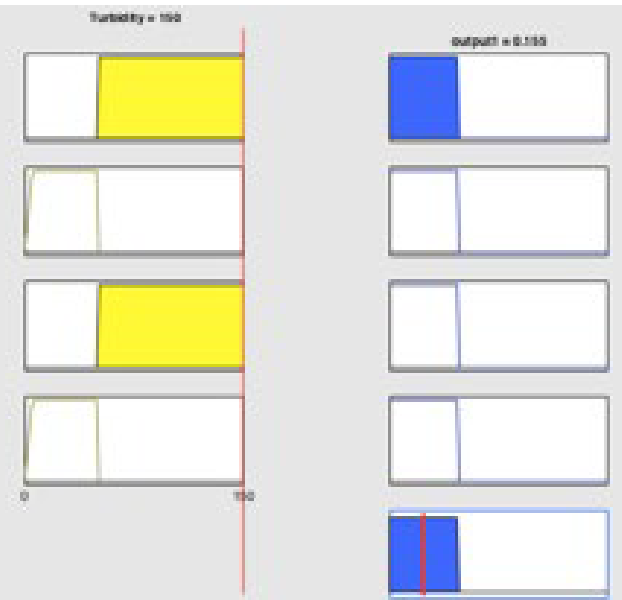

Chen, Q., Rui, H., Li, W., \& Zhang, Y. (2014). Analysis of algal bloom risk with uncertainties in lakes by integrating self-organizing map and fuzzy information theory. The Science of the Total Environment, 482-483, 318-24. Franz, C., Makeschin, F., Weiß, H., \& Lorz, C. (2013). Geochemical signature and properties of sediment sources and alluvial sediments within the Lago Paranoá catchment, Brasilia DF: a study on anthropogenic introduced chemical elements in an urban river basin. The Science of the Total Environment, 452, 411-20.

Gharibi, H., Mahvi, A. H., Nabizadeh, R., Arabalibeik, H., Yunesian, M., \& Sowlat, M. H. (2012). A novel approach in water quality assessment based on fuzzy logic. Journal of Environmental Management, 112, 87-95.

Mahapatra, S. S., Nanda, S. K., \& Panigrahy, B. K. (2011). A Cascaded Fuzzy Inference System for Indian river water quality prediction. Advances in Engineering Software, 42(10), 787-796.

Ocampo-Duque, W., Osorio, C., Piamba, C., Schuhmacher, M., \& Domingo, J. L. (2013). Water quality analysis in rivers with non-parametric probability distributions and fuzzy inference systems: application to the Cauca River, Colombia. Environment International, 52, 17-28. 